\title{
A COMPARISON OF OUTCOMES OF FOUR PORTS VERSUS THREE PORTS LAPAROSCOPIC CHOLECYSTECTOMY
}

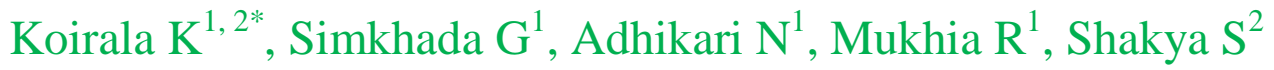 \\ ${ }^{1}$ Department of General Surgery, KIST Medical College and Teaching Hospital \\ ${ }^{2}$ Om Hospital \& Research Center P. Ltd \\ *Corresponding Author
}

Dr.Kamal Koirala, Associate professor of General Surgery,Department of General Surgery,KIST Medical College and Teaching Hospital, Email:drkkoirala@gmail.com

\section{ABSTRACT}

Background: Conventional laparoscopic cholecystectomy is performed using four ports. With increasing surgeon experience, there is a trend towards performing it using three ports. The aim of this study was to compare the three-port laparoscopic cholecystectomy with the conventional four-port technique in terms of safety, benefits and feasibility in a teaching hospital and private hospital setups.

Materials \& Methods: A retrospective review of medical records was performed on patients who underwent laparoscopic cholecystectomy at KIST Medical College and Teaching Hospital and Om Hospital \& Research Center P. Ltd by a single laparoscopic surgeon. The review included demographics, operating time, analgesics requirement, post- operative hospital stay and intra-operative and post-operative complications. The data were tabulated in MS-Excel and statistically analyzed using SPSS statistics software, version 21.

Results: There were 150 patients included in this study with 75 patients in each three and fourport groups. The demographics were comparable in both groups. $7.3 \%$ were diagnosed with acute calculous cholecystitis, $76.7 \%$ with chronic calculous cholecystitis and $3.3 \%$ were gall bladder polyps. Four-port technique was generally required for the acute calculous cholecystitis which was statistically significant. The three-port group had a shorter mean operative time than the four-port group. There was no statistically significant difference in the doses of analgesics requirement and mean post-operative hospital stay in both groups. There were no major intra and post-operative complications in both groups. Four-port technique was commonly done in teaching hospital and the three-port in private hospital.

Conclusions: There is significant number of laparoscopic cases being performed using three ports and we concluded that the three-port laparoscopic cholecystectomy is safe and feasible in experienced hand although there is no significant benefit. The study also showed an increasing use of four-port technique in the teaching institution which is better to clearly visualize the anatomy of the Calot's triangle. So we recommend using the four-port technique for teaching the beginners and as the experience is gained, we can gradually shift to three-port technique and at the same time we shouldn't hesitate to convert to four-port in difficult cases.

Keywords: Laparoscopic cholecystectomy 


\section{INTRODUCTION}

In 1987, Philip Mouret performed the first laparoscopic cholecystectomy in Lyon, France. ${ }^{[1,2]}$ After that, many surgeons started performing it and by 1992, it had already become the gold standard for the treatment of symptomatic gall bladder disease. [3] In Nepal, laparoscopic cholecystectomy began in 1994 and since then it had become one of the most commonly done procedure in general surgical practice. ${ }^{[4]}$ Traditionally, laparoscopic cholecystectomy is performed using four ports where the fourth port is used to grasp the fundus of the gallbladder to expose the Calot's triangle. ${ }^{[5]}$ However, with increasing surgical experience, there is a trend towards even more minimally invasive approaches like reduction in the number and size of the ports.

Many surgeons have reported that the fourth port is not necessary and the laparoscopic cholecystectomy could be done safely using three ports only. ${ }^{[5,6,7]}$ There are studies which showed three-port laparoscopic cholecystectomy results in less port-site pain, few surgical scar and similar clinical outcomes without any increased risk of complication compared with fourport laparoscopic cholecystectomy ${ }^{[6,7]}$ and there are studies which didn't show any added advantages of three-port technique. ${ }^{[8]}$ In Nepal, only one similar study has been published in PubMed comparing the three-port and four-port techniques which was done in the community based teaching hospital. ${ }^{[9]}$ No such studies have been published in private hospital setups. The primary objective of this study was to assess the safety, benefits and feasibility of three-port laparoscopic cholecystectomy over the conventional four-port technique in a teaching institution and in private hospital setups. The study would shed light if there is any advantage of using one less port while doing laparoscopic cholecystectomy and if it will cause any harms. Since the study was conducted in a teaching hospital and a private hospital, it will also show the trend in doing laparoscopic cholecystectomy in different setups

\section{MATERIALS AND METHODS}

\section{Study design and settings}

This is a multicentre study conducted in KIST Medical College and Teaching Hospital and Om Hospital \& Research Center P. Ltd. A retrospective observational study was done and data were collected of patients who underwent laparoscopic cholecystectomy by a single laparoscopic surgeon. The medical records of 150 patients who underwent laparoscopic cholecystectomy over 2 years (july4, 2016 to july3, 2018) by a single laparoscopic surgeon were reviewed after obtaining the approval from the institutional review committee. The exclusion criteria were those patients who also underwent other simultaneous procedure along with the laparoscopic cholecystectomy. The data collected were age, sex of the patients and diagnosis. Other variables that were collected were operating time (from beginning of incision to closure of the wound), complications (bile duct injury, bleeding). Analgesics requirement and post-operative hospital stay were also reviewed along with the surgical site infection within 30 days follow up period.

\section{Statistical Analysis}

All the observed data of the clinical characteristics of the patients and the outcome were tabulated in MS-Excel and statistically analysed using SPSS statistics software, version 21. 


\section{RESULTS}

Out of 150 patients, 37 were male and 113 were female. The male and female sex ratio 1:3.05. The age group was comparable in both groups with mean age $43.59 \pm 14.35$ years in three-port groups and $43.08 \pm 13.97$ years in four-port group as shown in table 1 . The three-port LC was performed in $75(50 \%)$ patients while the four-port LC was performed in $75(50 \%)$ patients. 80 $\%$ (60) of the three-port technique were performed in private hospital and $70 \%$ (53) of the fourport were performed in teaching hospital.

$7.3 \%$ were diagnosed with acute calculous cholecystitis and $76.7 \%$ with chronic calculous cholecystitis and $3.3 \%$ were gall bladder polyps as shown in table 2. Four-port technique was generally required for the acute calculous cholecystitis which was statistically significant.

The three-port group had a shorter mean operative time than the four-port group but wasn't statistically significant. The mean operative time for three-port group was $52.79 \pm 22.228 \mathrm{mins}$ and for four-port group was $63.29 \pm 26.635 \mathrm{mins}$. There was no statistically significant difference in the number of analgesics requirement in both groups. The mean post-operative hospital stay was $2.89 \pm 1.391$ days and 3.44 \pm 1.265 days in three-port and four-port groups which was also not statistically significant. There was no bile duct injury in both groups. Surgical site infection was seen in both groups but was not statistically significant. These results are summarized in table 3.

Table 1 Demographic Data

\begin{tabular}{|c|c|c|c|}
\hline Demographic data & Three-port group & Four-port group & P value \\
\hline Number (n) & 75 & 75 & 0 \\
\hline $\begin{array}{l}\text { Age (years) (Mean } \pm \\
\text { SD) }\end{array}$ & $43.59 \pm 14.55$ & $43.08 \pm 13.97$ & 0.218 \\
\hline \multicolumn{4}{|l|}{ Sex } \\
\hline Male & 20 & 17 & \\
\hline Female & 55 & 58 & \\
\hline
\end{tabular}

Table 2: Diagnosis

\begin{tabular}{lcccc}
\hline Diagnosis & $\begin{array}{c}\text { Three-port } \\
\text { groups }\end{array}$ & $\begin{array}{c}\text { Four-port } \\
\text { group }\end{array}$ & Total & Percent \\
\hline
\end{tabular}




\begin{tabular}{lcccc}
\hline Acute calculouscholecystitis & 0 & 11 & 11 & 7.3 \\
Gangrene & 1 & 0 & 1 & 0.7 \\
Mucocele & 3 & 6 & 9 & 6.0 \\
Empyema & 2 & 6 & 8 & 5.3 \\
$\begin{array}{l}\text { Chronic } \\
\text { calculouscholecystitis }\end{array}$ & 66 & 49 & 115 & 76.7 \\
Porcelain gall bladder & 0 & 1 & 1 & 0.7 \\
Gall bladder polyp & 3 & 2 & 5 & 3.3 \\
Total & 75 & 75 & 150 & 100 \\
\hline
\end{tabular}

Table 3: Outcomes

\begin{tabular}{lccc}
\hline Outcomes & Three-port groups & Four-port group & P value \\
\hline Operation time (min) & $52.79 \pm 22.228$ & $63.29 \pm 26.635$ & 0.555 \\
Post op hospital stay & $2.89 \pm 1.391$ & $3.44 \pm 1.265$ & 0.683 \\
$\begin{array}{l}\text { Analgesics } \\
\text { requirement }\end{array}$ & $2.85 \pm 0.512$ & $2.97 \pm 0.492$ & 0.102 \\
SSI & 4 & 4 & 0 \\
Bile duct injury & 0 & 0 & 0 \\
\hline
\end{tabular}

\section{DISCUSSION}

Since the introduction of the laparoscopic cholecystectomy in 1990s, it is now a gold standard in the treatment of symptomatic gall bladder diseases because of its advantages over open cholecystectomy in reducing the post-operative pain, and post-operative hospital stay and also in allowing patient an earlier return to work. ${ }^{[3]}$ With increasing experience, the laparoscopic cholecystectomy has undergone many modifications. Many surgeons don't use the $4^{\text {th }}$ port which is used to hold the fundus of the gallbladder. There have been many studies that have compared the three-port and four-port laparoscopic cholecystectomy but the conclusions in these studies are varied.

Many surgeons have expressed concerns about the safety of the three-port technique that it will result in more bile duct injuries since it is difficult to achieve the critical view of safety in threeport technique. However a local study done by Kumar et al compared in randomized controlled 
trial and found it technically feasible and safe. ${ }^{[9]}$ Another randomized controlled trial involving 200 patients undergoing elective laparoscopic cholecystectomy reported no difference in the outcome with no major complications with the three-port technique. ${ }^{[10]}$

In these studies, only those patients undergoing elective laparoscopic cholecystectomy were included. In our study, we have included both elective and emergency laparoscopic cholecystectomy involving patients with acute cholecystitis, mucocele and empyema. In our study also, we found the three-port technique to be safe with no major complications like bile duct injuries and bleeding. However, since the size of our study population is small and there is no randomization, we still need to perform prospective randomized study involving both elective and emergency laparoscopic cholecystectomy to address the concerns about the safety of the three-port technique.

In our study, we found that most of the acute cholecystitis patients were being operated by fourport technique. This could be because of the inflamed and distended gall bladder with thickened wall in acute cholecystitis which is easier and safer to operate if done with four-port technique and this could also explain the longer operating time for the four ports technique in our study.

Several studies have found the use of three-port didn't affect the procedure safety, conversion rate and operating time. These studies have also shown many benefits of doing a three-port laparoscopic cholecystectomy like less surgical site pain, short hospital stay and fewer scars. ${ }^{[9,}$ ${ }^{10,}{ }^{11]} \mathrm{A}$ meta-analysis comparing the three and four-port done by Sun et al showed similar operating times, success rate and post-operative hospital stay in both groups. ${ }^{[12]}$ In our study, the operative time also remains constant when compared to published series ${ }^{[13]}$ There was no significant difference between the two groups in terms of postoperative hospital stay which was comparable to other study. ${ }^{[14]}$ Harsha et al found significantly less postoperative hospital stay in three-port group compared with the four-port groups. ${ }^{[15]}$

One finding consistently noted in our study was that with the four-port technique, it was easier to visualize the anatomy in the Calot's triangle and hence we recommend that the four-port technique is better for teaching purpose and as the surgeons gain experience, then the three port technique can be performed without any risk of complication.

\section{CONCLUSIONS}

There is significant number of laparoscopic cases being performed using three ports and we concluded that the three-port laparoscopic cholecystectomy is safe and feasible in experienced hand although there is no significant benefit. The study also showed an increasing use of fourport technique in the teaching institution which is better to clearly visualize the anatomy of the Calot's triangle. So we recommend using the four-port technique for teaching the beginners and as the experience is gained we can gradually shift to three-port technique and at the same time we shouldn't hesitate to convert to four-port in difficult cases.

\section{REFERENCES}

1. Mouret P How I developed laparoscopic cholecystectomy. Ann Acad Med Singapore.1996; 25:744-747. 
2. Litynski GS. Profiles in laparoscopy: Mouret, Dubois and Perissat: the lapaaroscopic breakthrough in Europe JSLS. 1993; 163-167

3. Soper NJ, Stockmann PT, Dunnegan DL Ashley SW. Laparoscopic Cholcystectomy: the new 'gold standard'? Arch Surg 1992; 127(8) 917-923

4. Shrestha S, Pradhn G, Bhoomi K, Dhital A, Bhattachan CL. Review of laparoscopic Cholecystectomy in NMC-TH. Nepal Medical College Journal. 2007;9(1)

5. Afzul M, Rehman S (2016) An analysis of 3-port laproscopic cholecystectomy: How often 4th port is required? Journal of the College of Physicians of Sugeons Pakistan 2016, 26:163-164

6. Cerci C, Tarhan OR et al.Three port versus four port laparoscopic cholecystectomy. Hepatogastroenterology 2007,54:15-16

7. Koichev A. Comparative analysis of the four-ports and three-port trocar access of the conventonal laparoscopic cholecystectomy- review of the literature. Khirurgiia.2013

8. Al-Azawi D, Houssein N. Rayis AB, Mcmahon D, Hehir DJ Three-port versus four-port laparoscopic cholecystectomy in acute and chronic cholecystitis. BMC Surgery. 2007,7:8.

9. Kumar M, Agrawal CS, Gupta RK. Three-port versus standard four port laparoscopic cholecystectomy: a randomized controlled trial in a community based hospital in eastern Nepal. JSLS. 2007, $11:$ 358-362.

10. Chalkoo M, Ahangar S. Durrani AM. Is fourt port really required in laparoscopic cholecystectomy? Indian Journal of Surgery. 2010, 72: 373-376.

11. Sun S, Yang K, Gao M et al. Three-ports versus four port laparoscopic cholecystectomy: metaanalysis of randomizd controlled trials. World J Surg 2009;33:1904-1908

12. Trichak, S. Three-port vs standard four-port laparoscopic cholecystectomy. Surg Endosc. 2003;17(9): 1434-1436.

13. Slim K. Pezet D, Stenci J, Lechner C, Roux SL, Lointier P, Chipponi J. "Laparoscopic cholecysstectomy: an originla three trocar technique." World Journal of Surgery.1995; 19(3): 394-397

14. Ciftci A, Yazicioglu MB, Tiryaki C, Turgut T, Subasi O, Ilgoz M, Civil O. Is the fourth port routinely required for laparoscopic cholecystectomy? Our three-port lapascopic experience. Irish Journal of medical Science. 2016; 5(4):909-912

15. Harsha HS, Gunjiganvi M, Singh C et al. A sty of three port versus four-port laparoscopic cholecystectomy. J Med Soc. 2013;27:208-211 